\title{
Motivation in modern language studies: A pilot study in Italian language
}

\author{
Sandra Mardešić \\ Faculty of Humanities and Social Sciences, University of Zagreb, Croatia \\ smardesi@ffzg.hr \\ Ana Gverović \\ Faculty of Humanities and Social Sciences, University of Zagreb, Croatia \\ agverovi@gmail.com \\ Ana Puljizević \\ Faculty of Humanities and Social Sciences, University of Zagreb, Croatia \\ ana.puljizevic@gmail.com
}

\section{Introduction}

In the field of research on learners' individual differences (ID), the affective domain, motivation in particular, has been thoroughly examined (Dörnyei and Ryan, 2015). The interest in motivation in SLA dates back to the early 1950s and has since been a very prolific area of research. Recently, in the period between 2005 and 2015, over a hundred publications on motivation in SLA were published, in which a number of various constructs and factors have arisen, confirming that the motivation is a dynamic and complex process (Dörnyei \& Ryan, 2015). As a result, a large number of definitions of L2 learning motivation have been employed: from Gardner's (1985, p. 10) "the extent to which the individual works or strives to learn the language because of a desire to do so and the satisfaction experienced in this activity" to a broader definition by Medved Krajnović: "a set of motives, i.e. of psychological states that move and direct human behaviour and determine its intensity" (2010, p. 77). In this pilot study we shall use the latter definition.

\section{Theoretical background}

The most widely known motivation construct is Gardner's socio-educational model (Gardner,1985), which is based on the analysis of the relation between motivation and the social context, namely, the analysis of various bilingual communities in which the language 
of interest was learned or acquired. A later, revised version of this model (Gardner \& MacIntyre, 1993: 8), was based on cross-cultural research studies and it included the following dimensions: integrativeness, with subscales of integrative orientation, interest in foreign languages and attitudes toward L2 community, attitudes toward the learning situation, with subscales of evaluation of the L2 teacher and evaluation of the L2 course and motivation, with subscales of the desire to learn the L2, motivational intensity (effort) and attitudes toward learning the L2.

A change in this approach to motivation was brought by Dörnyei (1990), who based his premises on a longitudinal study of Hungarian students of English in a typical European FL learning context-characterised by scarce contact with native speakers and exposure to the target language that is mostly restricted to the classroom. Dörnyei reduced the importance of the role of attitudes towards the speakers and the target language community in achieving success in FL learning relative to Gardner's model. In fact, Dörnyei distinguishes between the instrumental and the integrative subsystem, linking the former to promotion (individual's desires and aspirations) and prevention (avoiding undesirable outcomes), and the latter to the interest in FLs, cultures and people, as well as to the desire to broaden one's horizons, find new challenges and fit into the global community. In 2005, Dörnyei added two more components to his model: the need for achievement and the attribution about past failures. Therefore, Dörnyei's L2 Motivational Self System consists of the following components: (1) a goal or need, (2) the desire to achieve a goal, (3) the understanding that FL language learning is crucial for achieving a goal or satisfying a need, (4) the belief in success or failure in the process of learning, and (5) the importance given to possible outcomes. This approach is oriented more to the individuals themselves, which is why motivation is related to the ideal L2 self, the ought-to L2 self, and to the L2 learning experience. In Dörnyei's model the ideal L2 self, namely, the representation of the learners' linguistic ideals, is seen as a continuous motivator. In our case, the students who choose to study a language at university level tend to have very high Ideal L2 Self standards, usually expressed as wanting to reach a high level of "native like" language proficiency. The ought-to L2 self, on the other hand, concerns the attributes that the learners, based on various intrinsic and extrinsic reasons, believe they should possess. Finally, the L2 learning experience is related to the teacher, the curriculum, the peer group, and the experience of success (Dörnyei, 2009). This latter part of the construct has not been researched sufficiently with specific populations and has therefore been the motivation for our pilot study.

In Croatian context of EFL learning as a school subject, Mihaljević Djigunović (1998) points out that, in this context, the type and the intensity of motivation change according to the teaching situation. She thus distinguishes between three types of motivation: the pragmatic-communicative (which corresponds to Gardner's instrumental orientation (1985) and Dörnyei's (1990) instrumental subsystem), affective and integrative motivation (Gardner's integrative orientation (1985) and Dörnyei's integrative subsystem (1990)). 
Mihaljević Djigunović also stresses the impact the initial motivation exerts on the results of language learning, as well as the role of various motivating and demotivating factors related to the teaching situation (Mihaljević Djigunović, 1998). This is comparable to Gardner's evaluation of the L2 teacher and evaluation of the L2 course (1985), as well as Dörnyei's L2 learning experience (1990).

Considering the formal, school -based context of FL learning, Balboni (2002) also highlights the role of the teacher and bases his model of motivation on duty, need and pleasure as three activating factors similar to those previously mentioned. Balboni asserts that duty is often connected to the context of learning a FL as a mandatory school subject and does not necessarily lead to success, while the need to master a FL (instrumental orientation) generates greater motivation and success. However, the process reaches its conclusion when learners satisfy their needs. The feeling of pleasure in the learning process and the fulfilment of a previously set goal, on the other hand, contribute to the growth of long-term intrinsic motivation and the continuity of the motivation, wherein teachers and the teaching situation greatly contribute to both.

In addition to the above-described factors that affect motivation, a high correlation between the success in FL learning and the intensity of motivation has been observed (e.g. Bernaus \& Gardner, 2008; Gardner \& MacIntyre, 1993; Guilloteaux \& Dörnyei, 2008). According to Gardner's socio-educational model (1985), there is a reciprocal relationship between motivation and success. Motivated students can find themselves in a positive environment in which they can achieve good results that would help them maintain their motivation and/or increase it. Alternatively, it is possible that poorly motivated students find themselves in a negative environment in which they cannot achieve good results, which results in an additional decrease in their motivation. Dörnyei (1998) and Ushioda (2001) highlight the fact that the nature of the stated correlation largely depends on the way in which an individual interprets their experience of FL learning and, consequently, on the manner in which they act. This implies that, while failure can motivate some students to work harder, it can also cause some students to become passive and lethargic. This relationship has not yet been researched enough on the student population of modern language university level programs.

In this pilot study we also apply Palotti's (2006) groups of reasons that motivate learners of FLs: instrumental, integrative, intrinsic, and extrinsic, wherein Palotti's instrumental motives can be long-term or short-term. The long-term instrumentally motivated individuals learn a FL to improve their social status and their career. University context implies a long-term studying period ( 3 years of undergraduate and 2 years of graduate study programs). Palotti's integrative motive can be general or specific. General integrative motivation stems from the desire to communicate with people from different cultures who belong to a different speech community and use a particular FL in their everyday communication (Dörnyei's sociocultural language use (1990) and Mihaljević 
Djigunović's pragmatic-communicative aspect (1998). This aspect is generally attributed to university students of FLs because communicating in a target language is the part of their future careers. Specific integrative motivation, on the other hand, arises from the desire to fit into an L2 community and to adapt to their culture. For Palotti (2006) the intrinsic motivation is determined by the situation in which language learning takes place. It is possible to distinguish between general intrinsic and specific motivation, the former related to language input and the latter related to a specific teaching situation. It is possible to observe general intrinsic motivation in individuals prone to FL learning (Gardner's integrative orientation (1985), Mihaljević Djigunović's affective motivation type (1998), and Dörnyei's integrative subscale (1990). Furthermore, De Mauro and his colleagues' study results confirm that the decision to enrol in Italian studies was indeed based on this specific type of intrinsic motivation (De Mauro, Vedovelli, Barni, Miraglia, 2002). Finally, Palotti's specific intrinsic motivation relates to a particular teaching situation that depends on the students' positive or negative perception of the teaching environment (Dörnyei's L2 learning experience (1990), Gardner's attitudes toward the learning situation (1985), and Mihaljević Djigunović's affective motivation type (1998).

However, all of the previously described models are based on research conducted with learners of L2 or FL in primary or secondary schools, with students that learn a FL for specific purposes, or adults that attend language courses.

Students of modern languages at university level are usually experienced language learners of the target language and the choice of pursuing it at university level implies a long term intrinsic or affective motivation, namely, these students have positive attitudes towards the speakers and community of the FL, as well as instrumental orientation intended at graduating and starting a professional career. Even though this population is highly motivated to study a FL, Busse and Walter (2013) report a decrease in motivation among university students of German in the UK due to various factors such as not achieving the desired level of proficiency and the lack of classroom interaction in FL. Ushioda's findings (2001) based on qualitative research done with Irish students of French language, highlighted the following motivational dimensions as the most reported: language-related enjoyment, desired level of L2 competence, personal goals and positive FL learning history. Holi (2015), based on her small-scale study conducted with students of Czech at the Faculty of Humanities and Social Sciences in Zagreb, highlighted various aspects which were confirmed in previously cited models. She reported some affective aspects, such as positive emotions and a relaxed atmosphere in the classroom, desire to learn about the target language culture and its speakers and the importance of the parents' and teachers' support. Her findings also include some of the learning situation aspects, such as elimination of unfavourable conditions of language learning, limited choice of courses, the fear of evaluation by the teacher and the peers and being embarrassed in front of the peers. 


\section{Study}

Our literature research on motivation in L2/ FL learning shows that there are relatively few studies focusing on the specific population of students in modern language programs for whom FLs are a career choice (Holi, 2015; Busse, 2013; Busse \&Walter, 2013; Ushioda, 2001). Based on these findings we designed our pilot study on the motivation in students of Italian at the university level by combining selected elements of the existing models (the integrative aspect, affective, intrinsic motivation, extrinsic factors) with associated questionnaires, by adapting these elements to our specific objective, and by exploring several additional aspects specifically related to the university level FL learning context.

\subsection{Context of the study}

We consider the students of Italian language at the Faculty of Humanities and Social Sciences in Zagreb the specific population of experienced FL learners of interest in our pilot study, which differs from students that learn Italian in private language schools or in high schools as their second or third FL because for them learning the language is a career choice. Due to the language policy in Croatia, that strongly emphasise learning of English or German as a first FL from the begginign of the primary school, Italian is usually second or third language, learned as an optional subject in elementary school or as an obligatory second FL in higschools. Students' aspiration at the time of enrolment is to reach a high "native like" level of proficiency at graduation $\mathrm{C} 1$ with elements of $\mathrm{C} 2$ according to CEFR, as prescribed by the university curricula. Furthermore, they are much more exposed to the Italian language at the university in comparison to the previous levels in primary or secondary schools. The university curricula require that all the lessons and the exams from the second year on are held exclusively in Italian, whereas in primary or secondary schools they had on average 70 hours of Italian lessons a year. So, the university students in our pilot study have frequent FL input through a large number of Italian literature, linguistics and culture courses held exclusively in the FL. In addition, they have many opportunities for out-of-classroom language use since Italy is a neighbouring country and many of the students visit it as part of the Erasmus program.

\subsection{Aim of the study}

The aim of our pilot study was to examine the dynamics and the typology of the motivation for students of Italian at the university level. We wanted to gain insight into the following aspects: a) the initial motivation for enrolment, b) the nature and intensity of the students' 
motivation, c) expectations and mismatches regarding the study programme and their career choice tendencies after graduation.

Our main research questions were the following:

RQ1: Are there any differences in the level of motivation between the groups (students year 1, year 2, year 3, year 4, year 5)?

RQ2: Are there any differences in the initial motivation and the motivation and the moment of conducting our pilot study within each group (years 1 to 5)?

RQ3: Which motivational dimensions can be identified?

RQ4: Are there any correlations between the success measured by the language exam grade, the overall success in the study program, the choice of Italian at enrolment, and the level of motivation measured by the instrument?

RQ5: What are the main motivating and demotivating factors in learning Italian at the university level?

\subsection{Participants}

The participants in the study were 173 students of Italian at the Faculty of Humanities and Social Sciences in Zagreb divided into groups of year 1 to 5 , which made $78.64 \%$ of the total number of students were enrolled in the program in the academic year 2015/16. The undergraduate students (year 1,2,3), constituted $69.36 \%$ of the total sample $(\mathrm{N}=120)$ whereas graduate students (year 4,5$)$ constituted the remaining $30.64 \%(\mathrm{~N}=53$, as shown

in Table 1. For $74 \%$ of them Italian was the first choice, which implies that the remaining $25 \%$ might have been potentially unsatisfied because they had different initial aspirations. All participants had studied Italian for 5 to 9 years, which means they had studied Italian before enrolling in the university: in their primary or secondary schools. Moreover, they had passed the mandatory entrance exam at the Department, which required that they be at least level A2 in Italian according to the official CEFR guidelines. Their professional aspirations after graduation were the following: (1) translation services (81 answer); (2) language teaching (59 answers); (3) tourism (31 answer), and other.

Table 1 shows the participants' average grade as a measure of success at their university level language study of Italian. We have noticed discrepancies between their overall average grade in the Italian program and their language proficiency measured by the language exam, which will be further discussed in the Discussion section. 
Table 1. Year of study, number of students whose first choice was Italian, grade average at the university and grade at their last Italian language exam $(\mathrm{N}=173)$

\begin{tabular}{|l|c|l|l|l|}
\hline Year of study & $\mathbf{N}$ & \multicolumn{1}{|c|}{$\begin{array}{c}\text { Italian was my } \\
\text { first choice }\end{array}$} & $\begin{array}{c}\text { Grade average } \\
\text { (1-5) }\end{array}$ & $\begin{array}{c}\text { Italian Language } \\
\text { exam (1-5) }\end{array}$ \\
\hline Year 1 & 27 & $70.37 \%(\mathrm{~N}=19)$ & 4.29 & 2.48 \\
\hline Year 2 & 46 & $71.74 \%(\mathrm{~N}=33)$ & 3.89 & 2.65 \\
\hline Year 3 & 47 & $70.21 \%(\mathrm{~N}=33)$ & 3.97 & 3.23 \\
\hline Year 4 & 27 & $81.48 \%(\mathrm{~N}=22)$ & 4,11 & 3.11 \\
\hline Year 5 & 26 & $80.77 \%(\mathrm{~N}=21)$ & 4.11 & 3.15 \\
\hline Total & 173 & $74.00 \%(\mathrm{~N}=128)$ & 4.07 & 2.93 \\
\hline
\end{tabular}

\section{Methodology}

Our pilot study was conducted using a mixed method approach, the most frequently used in recent motivation research (Lamb, Csizér, Alastair, Ryan, 2019). The first part of the questionnaire was used to collect quantitative data, the second part to gather qualitative data in form of open ended questions to gather more precise information about motivating and demotivating factors, while a focus group was used to obtain additional explanations of the quantitative data analysis.

\subsection{Questionnaire}

For the purpose of conducting our pilot study we created a new questionnaire adapted from already validated instruments based on models described in the Introduction.

Our questionnaire consisted of four parts: general data, motivation dimensions, five statements related to student's attitude toward and expectation from Italian FL study, and open-ended questions on reasons for enrolment, professional aspirations after graduation, and motivating and demotivating factors in the university program.

\subsubsection{General data and linguistic biography}

The first part of the questionnaire was used to gather the general data and linguistic biography from all participants: year of study, years of Italian language learning, success in FL learning measured by the average grade at the Italian study program and the language 
proficiency measured by the language exam grade. The language exam is the final exam in the mandatory Italian Language Course that examines the level of competences in all four language skills each year of study. The first-year students' success was evaluated based on their secondary school overall final grade and the grade they got in their last Italian language exam during their first year. The participants were asked to evaluate their motivation for enrolling in the Italian language and culture university program on a scale of 1 to 5 , both at enrolment beginning, and at the time the study was conducted. They were also asked to indicate whether Italian language study major was their first choice when enrolling at the university. This was done because in the admission process at the Faculty of Humanities and Social sciences students list their desired study majors in the order of preference, but their final enrolment in a major depends on their total score, which includes secondary school grade average, the overall score at final national exams and scores in selected subjects, and the score at the university entrance exam. As a consequence, for some of the participants in the study the Italian program was the first choice, while for others it was not.

\subsubsection{Motivation construct in our pilot study}

This part of the questionnaire examines the participants' motivation by piloting a construct which consists of the following components: integrativeness, instrumentality, the intensity of motivation, the teaching situation and family support. This part of the questionnaire consisted of 33 Likert scale statements ranging from 1 ("I strongly disagree") to 5 ("I strongly agree').

Integrativeness: University-level language students that have chosen Italian have to take a number of courses on the Italian language, literature and culture and also tend to travel to the country. The purpose of this dimension is to determine whether the students have positive attitudes toward the Italian language and Italians. This was accomplished by including four statements testing for integrativeness: our statement number 3 was taken from Gardner's 2004 AMTB questionnaire, which deals with attitudes towards the target language. Our statements 15 and 24, which address the desired level of similarity to the target community and the desire to get better acquainted with the target language culture and its speakers, were taken from Dörnyei's model (Clément, Dörnyei \& Noels, 1994). Our statement 32 tests the attitude of the students towards Italians as possible life partners and was taken from Mihaljević Djigunović's (1998) questionnaire.

Instrumentality: This dimension tests the nature of a specific goal a student wants to accomplish by learning the FL. To this end, our statements 5 and 8 were taken from Mihaljević Djigunović's questionnaire (1998) addressing the desired level of proficiency measured by the desired grade on the Italian exam and the desire to move to Italy. Students of Italian have one of the highest rates of Erasmus exchange programs participation. 
Intensity of motivation: This dimension tests Gardner's dimension of motivational intensity (effort) and desire to learn FL and tests demotivation caused by a lack of success, the presence of which was confirmed in a foreign language anxiety research conducted with Croatian students at the same institution, The Faculty of Humanities and Social Sciences (Mardešić \& Stanković, 2013; Puškar 2013). The questionnaire includes seven statements 9, 2, 10, 19, 22, 29, 31 from Gardner's AMTB (2004), with statement 9 adapted so that it refers to finding a job after graduation. Demotivation was tested with statement 27, which is a part of the CROEFLA questionnaire (Foreign Language Anxiety of Croatian EFL Learners, Mihaljević Djigunović et al., 2004).

Teaching situation: As noted in the introduction, university-level FL learning context can have a profound impact on the FL student motivation. To assess this properly, we devoted seventeen (more than half of the) statements in the questionnaire. Seven statements $(1,4,7,13,17,30,33)$, taken from Gardner's 2004 AMTB questionnaire, address the learning situation, which includes the evaluation of the FL teacher and the FL course. Four statements $(6,18,26,28)$, taken from Mihaljević Djigunović's (1998) questionnaire, specifically address the role of the teacher in the Croatian FL learning context, with issues such as the teacher's feedback and the evaluation of teaching materials. Statement 21, addressing the usefulness and quality of the courses, is taken from Dörnyei's model (Clément, Dörnyei \& Noels, 1994). Two statements $(12,20)$ are part of the CROEFLA questionnaire (Mihaljević Djigunović et al., 2004) and refer to the perceived difficulty of Italian grammar and the competitiveness among the students, the former being an issue addressed in previous research by Holi (2015).

The three remaining statements $(11,14,16)$ were constructed by the authors of this paper to include the particular aspect of the university learning context, not included in the aforementioned questionnaires. These three statements assess language anxiety as was previously found among students of the same university (Mardešić \& Stanković, 2013; Puškar, 2013).

Family support: This part consists of statement 25, taken from Gardners's AMTB questionnaire (2004). This aspect has also been included in other models and research (Clément, Dörnyei \& Noels, 1994; Holi, 2015; Mihaljević Djigunović, 1998).

\subsubsection{Course expectations}

The third part of the questionnaire consisted of 5 statements that test the attitudes towards and expectations from the university study program in the Italian language and culture at the Faculty of Humanities and Social Sciences of Zagreb. Here, as well, we used a 5-point Likert scale. The participants were asked to estimate their satisfaction with the courses, the effort they put in, and their perceived success in learning. 


\subsubsection{Initial motivation, motivating /demotivating factors, future job aspirations}

The final part of the questionnaire consisted of four open-ended questions: two were used to assess the demotivating factors the students had come across during their studies, while the other two inquired into the students' initial motivation for enrolling in the Italian language program and their career aspirations after graduation. The latter two questions were adopted from Italiano 2000 (De Mauro et al., 2002), a study that was used to collect data on the ways in which Italian spread worldwide and the conditions under which this expansion happened.

\subsection{Procedure and analysis}

The study was conducted in two phases. In the first phase, the participants were asked to fill in the questionnaire during their compulsory lectures, while their lecturers were absent and two students, authors of this paper were present. Quantitative data were analysed using SPSS, whereas quantitative data were analysed using content analysis. All qualitative answers were first analysed and categorised by the two student researchers and subsequently discussed and re-categorised together with a third researcher. Upon completion of the first phase, 30 participants, primarily students of years 3,4 and 5, volunteered to become a focus group and participate in the second phase of the study. These participants were shown the results of the qualitative data analysis and were asked to elaborate on them. Their answers were subsequently transcribed and analysed by all three researchers, after which they were categorised.

\section{Results}

\subsection{Results of the quantitative analysis}

The reliability of the 33 statements used in the questionnaire was verified using Cronbach's alpha, which indicated a high degree of internal consistency $(\alpha=0.897)$, so all of the statements were kept in further data analysis. The internal consistency test for single components showed medium reliability degree for integrativness scale $(\alpha=0.635)$, and high degree for scales of intensity of motivation $(\alpha=0.806)$ and teaching situation $(\alpha=0.865)$. The remaining two scales, instrumentality and family support, had a low number of statements and were not suitable for test of the internal consistency. For this reason, these last two components will be discussed only qualitatively. 
The descriptive analysis of the whole sample showed that the participants were moderately motivated $(M=109, S D=18.05)$, and the intensity of their motivation ranged from 64 to a maximum of 150 (Figure 1).

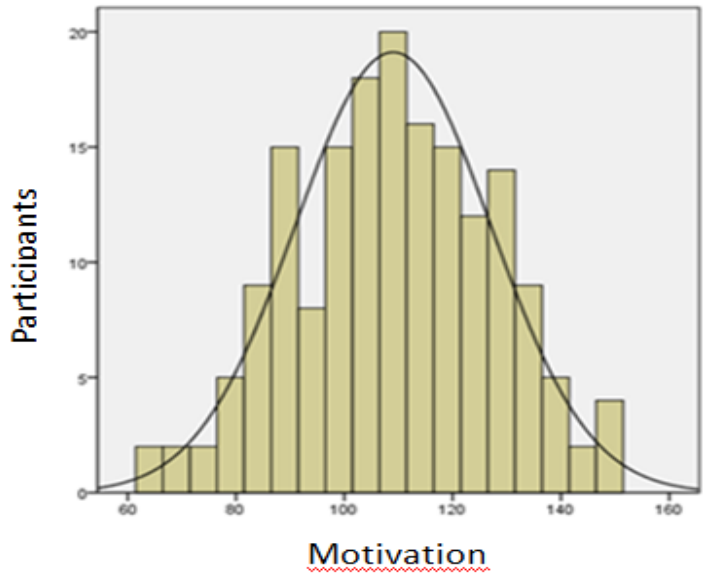

Figure 1. The intensity of motivation within the entire sample (N=173).

We find that the answer to RQ1 is affirmative as the analysis points to differences between the groups (year 1, year 2, year 3, year 4, year 5) in their motivation measured by our instrument (Table 2). The variance analysis showed statistically significant differences between year 1 and year 5 students' motivation ( $F=3.082, p=0.019)$. A noticeable drop in the overall motivation was observed between year 1 and year 2 , but not at a statistically significant level, $\mathrm{p}=0.185$ (Table 2). The year 3 group, undergraduates, and year 4 group, graduates, report almost the same level of motivation (Table 2). In addition, it should be noticed that the results of the overall motivation per group point to a decrease in scores with the increase of the year of study (Figure 2).

Table 2. Overall motivation average per year of study $(\mathrm{N}=173)$

\begin{tabular}{|l|c|c|c|}
\hline Year of study & Mean & N & SD \\
\hline Year 1 & 119.26 & 27 & 19.934 \\
\hline Year 2 & 108.54 & 46 & 17.252 \\
\hline Year 3 & 107.32 & 47 & 15.016 \\
\hline Year 4 & 107.48 & 27 & 18.958 \\
\hline Year 5 & 103.73 & 26 & 18.791 \\
\hline Total & 108.99 & 173 & 18.050 \\
\hline
\end{tabular}

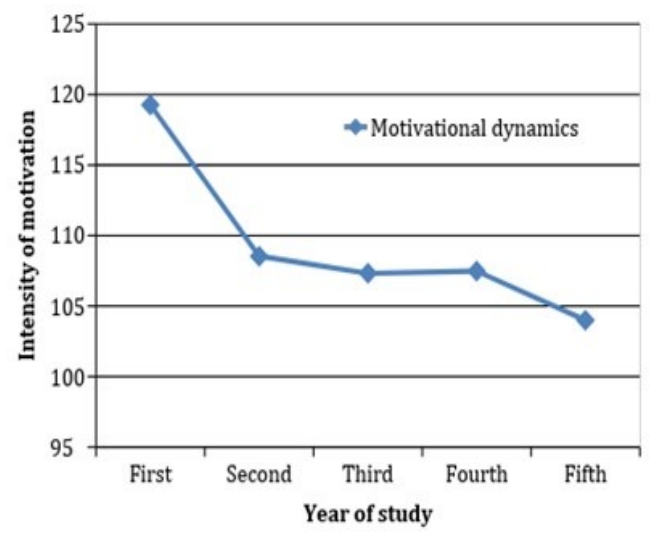

Figure 2. Motivational dynamics per year of study $(\mathrm{N}=173)$ 
Our second research question (RQ2) about differences in the initial motivation and the motivation and the moment of conducting our pilot study, we also had an affirmative answer, because the t-test results showed a statistically significant difference between the self-evaluated initial motivation and the self-evaluated motivation at the time of the study in each group (Table 3).

Table 3. T-test results for self-evaluated initial motivation and the motivation at the time of the study per year of study ( $\mathrm{N}=173)$.

\begin{tabular}{|l|l|l|l|l|}
\hline Year of study & \multicolumn{1}{|c|}{$\mathbf{N}$} & \multicolumn{1}{|c|}{ t } & \multicolumn{1}{|c|}{ df } & sig. \\
\hline Year 1 & 27 & 3.174 & 26 & 0.004 \\
\hline Year 2 & 46 & 3.379 & 45 & 0.002 \\
\hline Year 3 & 47 & 6.144 & 46 & 0.000 \\
\hline Year 4 & 27 & 3.882 & 26 & 0.001 \\
\hline Year 5 & 26 & 4.765 & 25 & 0.000 \\
\hline
\end{tabular}

For our third research question (RQ3) which motivational dimensions can be identified, we present the results for those questionnaire statements from the second part that showed the highest scores, from the third part those which showed the course expectations and the results of qualitative data analyses. These results showed that the participants were mostly integratively motivated, namely, they reported specific and general intrinsic reasons for their FL learning. They had positive attitudes toward the language, its culture, its speakers, and desired a high level of proficiency.

Table 4. Statements with highest score for integrative motivation ( $N=173)$.

\begin{tabular}{|c|l|l|} 
Statement number & \multicolumn{2}{c|}{ Statement } \\
\hline 3 & Italian is a very nice language. & $\mathrm{M}=4.70 \mathrm{SD}=0.630$ \\
\hline 29 & I want to perfect my knowledge of Italian. & $\mathrm{M}=4.55 \mathrm{SD}=0.780$ \\
\hline 24 & $\begin{array}{l}\text { I would like to get to know the Italians, their } \\
\text { culture and tradition better. }\end{array}$ & $\mathrm{M}=4.23 \mathrm{SD}=0.953$ \\
\hline 31 & $\begin{array}{l}\text { I am eager to learn everything there is to } \\
\text { know about the Italian language. }\end{array}$ & $\mathrm{M}=4.02 \mathrm{SD}=1.043$ \\
\hline
\end{tabular}

The qualitative analyses also showed the same dimensions; the most cited reasons for enrolling in Italian language program were:

1) love of the Italian language (104 answers); 
2) love of Italy and Italian culture (34 answers);

3) desire to perfect linguistic competence (23 answers);

4) interest in FL in general (18 answers).

The initial instrumental orientation for enrolling is, however, also recorded in our qualitative analyses, and the desire to integrate into an Italian speaking community is present, though only in seven answers. The reasons provided were as follows:

1) the desire to use Italian in my future professional career (14 answers);

2) the participants' self-perceived linguistic competence (17 answers), e.g." I was very interested in the [Italian] language and I believe languages are something I am very good at and something I could base my future professional career on."

3) integrative motives (7 answers); e.g. "Because I want to master Italian and I might even want to move to Italy one day."

The qualitative data related to the teaching situation dimension are divided into motivating and demotivating aspects, which are further subdivided into internal (intrinsic) and external (extrinsic) motivators and demotivators.

The internal motivating factors partially correspond to the reasons for enrolling, which is why most of the answers are related to the following statements:

1) desire to perfect linguistic competence (32 answers)

2) love of the Italian language ( 24 answers)

3) love of Italy and Italian culture (12 answers)

4) desire to obtain a college degree and find a job related to it (12 answers).

The external motivating factors, on the other hand, are related to the following statements:

1) the professors (38 answers), e.g." What motivates me the most is when the professors themselves are motivated for work, when they try hard to pass on information and knowledge and when the courses are well designed."

2) the appropriateness, the purpose and the selection of courses (15 answers), e.g." [What motivates me is that] the amount of knowledge I 'get' during one semester is enormous, especially in relation to my secondary school education. [...] and I believe to be very good at learning Italian."

3) the teaching situation (12 answers), e.g." I was motivated by the pleasant atmosphere during the lectures and the effort some professors put into explaining some important concepts to the students."

The internal demotivating factors the students indicated were the following:

1) 'holes in knowledge' (13 answers)

2) falling behind one's peers (8 answers)

3) failure (4 answers).

These issues were corroborated by the score for statement 3: 'The Italian language studies course takes a lot more effort than I expected.' ( $M=3.18, \mathrm{SD}=1.181$ ). 
Among the external demotivating factors, the most prominent ones were as follows:

1) the teaching situation (93 answers), e.g. 'Unfair grading system, failure to implement the Bologna Process, insufficient professor effort, unclear learning outcomes'

2) the appropriateness, the purpose and the selection of courses (60 answers), e.g. "I believe that the selection of elective linguistics and literary courses is not wide enough. I feel that the offered courses were not designed to introduce the students to as many aspects of Italian culture and language as possible, but to suit the professors' preferences."

3) the professors (52 answers), e.g. "The courses where professors demand a lot from their students but offer little in return."

These issues are also confirmed by the score for the statements about curriculum expectations in the third part of the questionnaire: Statement 2: 'The Italian language studies have met my expectations' ( $M=2.47, \mathrm{SD}=1.124)$, but not at the level that the students regret their choice, as expressed by the score for statement 1: 'Sometimes I regret my choice of Italian studies.' ( $\mathrm{M}=2.87, \mathrm{SD}=1.459$ ).

The importance of parental support was recorded by a high score on statement 25: 'My family supports me in my studies.' (M=4.57, $\mathrm{SD}=0.809)$.

In the answers to our fourth research question (RQ4), the analysis revealed a statistically significant correlation in the following four variables: overall motivation measured by the instrument, Italian as the students' first choice when enrolling at the university, grades obtained in language exams, and the students' self-assessed current motivation for studying. Table 5. Correlations between the variable of Italian as the first choice, motivation measured by the research instrument, self-evaluated motivation at the time of the study and language exam grade $(\mathrm{N}=173)$.

\begin{tabular}{|l|l|c|c|c|}
\hline & $\begin{array}{l}\text { Italian as } \\
\text { the first } \\
\text { choice }\end{array}$ & $\begin{array}{l}\text { Overall } \\
\text { motivation }\end{array}$ & $\begin{array}{l}\text { Language } \\
\text { exam } \\
\text { grade }\end{array}$ & $\begin{array}{l}\text { Motivation } \\
\text { at the time } \\
\text { of the study }\end{array}$ \\
\hline Italian as the first choice & & $0.260^{* *}$ & 0.126 & 0.147 \\
\hline Overall motivation & $0.260^{* *}$ & & $0.317^{* *}$ & $0.742^{* *}$ \\
\hline Language exam grade & 0.126 & $0.317^{* *}$ & & $0.400^{* *}$ \\
\hline Motivation at the time of the study & 0.147 & $0.742^{* *}$ & $0.400^{* *}$ & \\
\hline
\end{tabular}

${ }^{* *} p<0.01$

The scores for the following two statements regarding the participants' selfperception of success in their studies indicate that they are moderately satisfied with themselves and confident in reaching their goal:

'I consider myself successful in my Italian studies' (M=3.40, SD=1.028). 
'I'm afraid that I will never be able to use Italian with ease' $(M=2.54, S D=1.353)$

\subsection{Results of the focus group data analysis}

The focus group participants were presented with the changes in motivation exhibited in Table 2 and Figure 2. When asked to interpret the oscillations in motivation during their studies, they explained that the decrease in motivation following the completion of year 1 courses was the result of the students' expectations that studying a language at the university level would be similar to that at the secondary school level. The lack of information on the study programme of their choice was another factor that contributed to the decrease. The focus group participants stated that they hadn't consulted the study program of the Department before enrolling. When asked about the unchanged motivation level exhibited between year 3 and the year 4 in Figure 2, the focus group hypothesized that the motivation that made them successfully complete their B.A. degree (year 3) most likely made them want to continue their FL study to and obtain the M.A. degree. Other reasons given to explain the decrease in motivation are as follows:

1) the students' own incorrect perception of what language studies entail

2) fearing that their choice of major may not offer many job opportunities, they questioned their decisions to take up Italian studies

3) their discontent with how both the University and the Department are organised

4) the lack of in-class pedagogy

5) a heavy student workload, due to the courses being held in Italian.

\section{Discussion}

This study has confirmed that motivation in FL learning at university level is a complex and dynamic process, as has been shown in other previous studies (Ushioda, 2001; Busse \& Walter, 2013; Holi, 2015). The results showed that the participants were mostly integratively or intrinsically motivated for Italian language learning. We therefore conclude that the dimensions described by Gardner's, Palotti's, Dörnyei's, Mihaljević-Djigunović's research apply to this specific population. The participants' choice of Italian studies was predominately based on intrinsic motives described in the qualitative analyses paragraph and these results are in line with De Mauro's (2002) research. Furthermore, the qualitative analyses about motivating factors during the studies indicate that the participants mostly remained intrinsically motivated, namely, they studied the language they liked and continued to like it, as cited in Balboni's model (2002). The students of other FLs at the university level highlighted positive attitudes toward the language, culture and its speakers, as well as language-related enjoyment (Busse \& Walter, 2013; Holi, 2015; Ushioda, 2001). 
A number of issues were found to have an effect on the intensity of motivation. These include the students' expectations about the university program, their success in the language learning, as well as motivating and demotivating factors and language anxiety, all of which are linked to specific teaching situations.

First, the data in Table 1 show that the participants' Italian language exam grades are consistently lower than their overall grades, while their motivation in the year of study decreased relative to the initial motivation in each year (Table 3). This clearly indicates that the students' perception of success in their studies is based on their language exams and not on their overall success. The results of correlations shown in Table 5 indicate that students who had better grades in language exams had a high level of motivation at the time the study was conducted. The answers to the questions about the internal demotivating factors also show that the participants considered their own lack of success to be a demotivating factor, which does not necessarily lead to putting in more effort, as suggested by Gardner (1985). These results are comparable to those obtained by the students of German (Busse \& Walter, 2013) and French (Ushioda, 2001), who stated that they hadn't reached the desired high level of proficiency.

However, in interpreting the results, it is important to consider the promotion and the prevention aspects of motivation, the former including the participants' desires and aspirations, whereas the latter refer to unwanted consequences (Dörynei, 2005). The decrease in motivation during their studies can also be interpreted as the consequence of the participants' realisation that language studies required more effort than they were ready to put in. As the students progress through the university study, they tend to become more aware of the fact that acquiring an FL is a lifelong process and that completing the studies does not necessarily mean reaching a high level of linguistic competence. This, in turn, exerts a negative impact on their motivation. This conclusion is further confirmed by the high percentage of agreement with the statements which deal with the desire to perfect one's Italian language skills. In other words, there is a wide gap between the participants' ideal L2 self and their ought-to L2 self (Dörnyei, 2009), which is why a decrease in their motivation is detected.

The prevention aspect of motivation is visible in the reported importance of parental support. Parental support was included in the previously cited motivational models (Gardner, 1985; Mihaljević Djigunović, 1998; Dörnyei, 1998), where it mainly referred to encouraging a child to learn an FL or otherwise inscribing a positive attitude toward FL learning or other language communities. For this reason, the importance of parental support gradually decreases with age (Gardner, 2007) and hence one would not expect to find it at the university level. In order to explicate our finding, we note that many participants were financially supported by their parents during their studies and hence their success at the university was potentially instrumental in preventing a conflict with their parents. The 
importance of parental support at the university level was also found in Ushioda (2001) and Holi (2015).

A decrease in motivation after the first year of study can be explained by the discrepancy between the idea that freshmen have of Italian studies and what the FL studies program actually entails. For instance, qualitative data in this study showed that the participants did not relate a number of linguistics and literary courses to FL learning. It could therefore be concluded that year 1 students expected to see university-level FL learning as a continuation of the secondary school approach, which includes strong emphasis on the communicative approach and development of language skills. The students of German in the UK (Busse, 2013; Busse \&Walter, 2013) also expressed a higher level of satisfaction with their secondary school learning of German in respect to the university-level learning. They, as well as Irish students of French, reported infrequent classroom interaction in FL, as literature and linguistics courses were held in their mother tongue (Ushioda, 2001). The former was not the case with our participants, since starting from year 2, all the courses and exams are held exclusively in the target FL, but this, on the other hand, discourages the less proficient students or suggests a possible lack of interaction in certain courses. As internal demotivating factors, our participants report lack of knowledge, falling behind and a feeling of failure.

In the teaching situation dimension or attitudes towards the course, one of the important demotivating external factors recorded in this study was discontent with the study program and with the way both the University and the Department were organised. These factors represent peculiarities of learning an FL at the university level. A learner who is not satisfied with a language course in a private FL school can drop out or change the school. In secondary school education, the teacher's task is to adapt the prescribed curriculum to the needs of individual students and to their differences. At the university level, however, a student has no impact on the curriculum. This issue also appears in Ushioda's (2001) and Holi's findings (2015), where the participants report the fact that they can't change course options as a demotivating factor.

The importance of the teacher's support in motivation was confirmed in our study, same as in the models described in the Introduction. The participants often highlighted the lack of in-class pedagogy during the lectures, the fear of being evaluated by their professors, the lack of stimulation, the insufficient effort of professors' efforts, and unsatisfactory teaching methods. Despite the fact that the students involved in this study are adults enrolled in a university degree program, they report on the same issues as the findings by Ushioda (2001), who points out that a good choice of teaching methods is crucial in maintaining intrinsic motivation regardless of the students' age. The same issue was brought up by the students of Czech at the same Faculty (Holi, 2015). This finding is also confirmed by the pedagogical implication for first-year university students of German as proposed by Busse and Walter (2013). It should be added that the lack of pedagogical skills of the teachers at 
the college level is also confirmed as a cross cultural demotivator for students in Japan, China, United States and Germany (Zhang, 2007).

\section{Conclusions}

Although L2 motivation has been thoroughly explored, there is scarce research on FL majors' motivation. It has been generally assumed that these learners are highly motivated at this stage of their education and that their motivation will either grow or remain unchanged, allowing for occasional variations. The results of this study indicate that motivation for FL learning at the university level is a process that is equally dynamic as that of FL learning in other contexts. The fact that students themselves enrol in modern language programs and choose FLs as their future profession does not necessarily mean that they do not come across a number of difficulties, as other learners do. We conclude that the approach to motivation of these specific populations should not differ from the general approach to motivation in FL learning.

The motivation dimension resulting from this study is based on intrinsic motives and integrative orientation, as well as aspirations, success and preventing failure. However, the teaching situation and the perception of success have an important effect on both general and specific intrinsic motivation. The university FL learning context includes some specific components, such as the university program curriculum, the outcomes of certain courses, the teaching methods and FL classroom use, the pedagogic component, as well as parental support and self-perception of success.

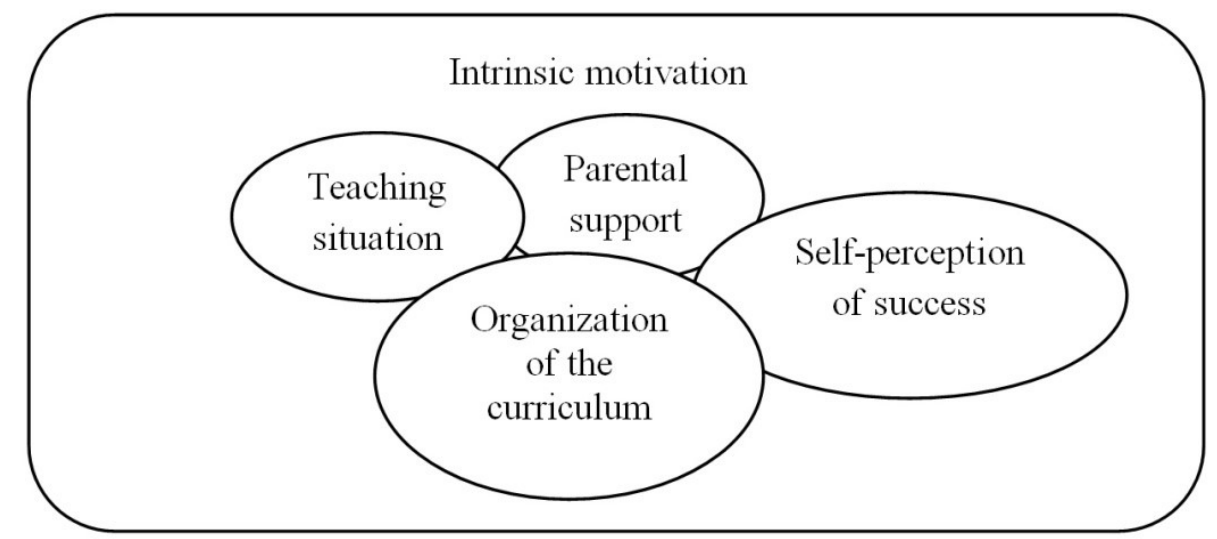

Figure 3. The proposed model of FL students' motivation at the university level

Our proposed model for FL students' motivation at the university level is schematically illustrated in Figure 3, where the four different dimensions of motivation organization of the curriculum, self-perception of success, parental support and teaching situation - are all embedded in intrinsic motivation. 
Our questionnaire displayed satisfactory measuring characteristics, but it should still be tested on a sample of students of other FLs. In accordance with the results, other specific components should be included as well. In the methodological context, this study confirmed the importance of a mixed-method approach, the use of open-ended questions and focus groups, as they help in clarifying specific issues that cannot be tested by questionnaires. The questionnaire we piloted can be used for improving the quality of the lectures and the programs and to gain insight into the common components specific to university student population.

As a pedagogical implication of this pilot study, we suggest presenting and explaining study programs to students, providing clear outcomes of specific courses, giving feedback more often and creating a positive learning environment through the entire duration of studies. It is important to note that the encouragement of self-regulated learning and selfmotivation techniques that can be perfected throughout the study are of importance as well.

\section{References}

Balboni, P.E. (2002). Le sfide di Babele. Torino: UTET.

Bernaus, M. \& Gardner, R.C. (2008). Teacher Motivation Strategies, Student Perceptions, Student Motivation, and English Achievement. The Modern Language Journal. 92(3), 387-401.

Busse, V. (2013). Why do first-year students of German lose motivation during their first year at university? Studies in Higher Education. 38(7), 951-971.

Busse, V. \& Walter, C. (2013). Foreign Language Learning Motivation in Higher Education: A Longitudinal Study of Motivational Changes and Their Causes. The Modern Language Journal. 97(2), 435-456.

Clément, R., Dörnyei, Z. \& Noels, K. (1994). English Language Learning Survey. Motivation, Self -confidence, and Group Cohesion in the Foreign Language Classroom. Language learning. 44(3), 417-448.

De Mauro, T., Vedovelli, M., Barni M. \& Miraglia L. (2002). Italiano 2000: i pubblici e le motivazioni dell'italiano diffuso fra stranieri. Rome: Bulzoni.

Dörnyei, Z. (1990). Conceptualizing Motivation in Foreign Language Learning. Language Learning. 40(1). 45-78.

Dörnyei, Z. (1998). Motivation in second and foreign language learning. Language teaching. 31(3), 117-135.

Dörnyei, Z. (2005). The psychology of the individual language learner: Individual differences in second language acquisition. Mahwah: Lawrence Erlbaum.

Dörnyei, Z. (2009). The L2 Motivational Self System. In Z. Dörnyei \& E. Ushioda (Eds.) Motivation, language identity and the L2 self (pp. 66-97). Bristol: Multilingual Matters. 
Dörnyei, Z. \& Ryan, S. (2015). The Psychology of the Language Learner Revisited. New York: Routledge.

Gardner, R.C. (1985). Social Psychology and Second Language Learning - The Role of Attitudes and Motivation. London: Edward Arnold.

Gardner, R.C. (2004). Attitude/Motivation Test Battery: International AMTB Research Project (English version). The University of Western Ontario. Retrieved June 6, 2018 from http://publish.uwo.ca/ gardner/docs/englishamtb.pdf

Gardner, R.C. (2007). Motivation and second language acquisition. Porta Linguarum 8, 9-20.

Gardner, R.C. \& MacIntyre P.D. (1993). A student's contributions to second-language learning. Part II: Affective variables. Language Teaching. 26. 1-11.

Guilloteaux, M. J. \& Dörnyei, Z. (2008) Motivating Language Learners: A Classroom-Oriented Investigation of the Effects of Motivational Strategies on Student Motivation. TESOL Quarterly, 42(1), 55-77.

Holi, A., (2015) Motivacija hrvatskih studenata za studij češkog jezika i književnosti (Diplomski rad, Filozofski fakultet Sveučilišta u Zagrebu, Zagreb, Hrvatska). Retrieved June 26, 2018 from http://darhiv.ffzg.unizg.hr/id/eprint/8831/1/Diplomski\%20rad -A.Holi.pdf

Lamb, M., Csizér, K., Alastair, H., Ryan, S. (2019). The Palgrave Handbook of Motivation for Language Learning. Cham: Palgrave Macmillan.

Mardešić, S.; Stanković, S. (2013). A Comparative Study of Foreign Language Anxiety Among Students Majoring in French, Italian and Spanish, in: UZRT: Empirical studies in English applied linguistics, Pécs: Lingua Franca Csoport, pp. 68-79.

Medved Krajnović, M. (2010). Od jednojezičnosti do višejezičnosti. Uvod u istraživanje procesa ovladavanja inim jezikom. Zagreb: Leykam international.

Mihaljević Djigunović, J. (1998). Uloga afektivnih faktora u učenju stranog jezika. Zagreb: Filozofski fakultet Sveučilišta u Zagrebu.

Mihaljević Djigunović, J. et al. (2004). Foreign language anxiety of Croatian EFL learners: Construction of an anxiety scale. In D. Kučanda, M. Brdar \& B. Berić (Eds.) Teaching English for Life: Studies to Honour Professor Elvira Petrović on the Occasion of her Seventieth Birthday. (pp. 115- 126). Osijek: Filozofski fakultet, Sveučilište Josipa Jurja Strossmayera u Osijeku.

Pallotti, G. (2006). La seconda lingua. Milano: Bompiani.

Puškar, Krunoslav (2013). A Comparative Study of Foreign Language Anxiety Among Majors of English and German, [ur. Judith Dombi et al.], Pécs, UZRT: Empirical studies in English applied linguistics, Pécs: Lingua Franca Csoport pp. 80-93.

Ushioda, E. (2001). Language learning at university: exploring the role of motivational thinking. In Z. Dörnyei \& R. Schmidt (Eds.) Motivation and second language 
acquisition. (pp. 93-125). Honolulu: University of Hawaii, Second Language Teaching and Curriculum Center.

Zhang, Q. (2007). Teacher misbehaviours as learning demotivators in college classrooms: A cross-cultural investigation in China, Germany, Japan and the United States. Communication Education, 56, 209-227.

\section{Appendix}

Questionnaire items

Integrativeness

(3) Italian is a very nice language

(15) I want to be more like the Italians.

(8) I want to master Italian to be able to live in Italy.

(24) I would like to get to know the Italians, their culture and tradition better.

(32) I would like to have an Italian partner.

Instrumentality

(9) I am losing my will to study because I think I will not be able to find a job related to my degree. *

(20) I try hard to achieve the best results possible to earn the respect of my colleagues.

\section{Motivation Intensity}

(6) I wish I had taken up another foreign language. *

(10) I put a lot of effort into studying Italian.

(27) I am losing my will to study Italian because of holes in my knowledge. *

(29) I want to perfect my knowledge of Italian.

\section{Teaching situation}

(1) My professors' enthusiasm motivates me to study.

(4) I feel uncomfortable when I have to use Italian during lectures. *

(7) I feel comfortable and relaxed during Italian lectures.

(11) My professors encourage me to have confidence in my abilities.

(12) Italian grammar is hard to acquire. *

(16) Frequent feedback on homework and assignment papers motivates me.

(18) I would be motivated to study if the lectures were more interesting. *

(21) Most of the courses our Department offers are interesting and useful. 
(23) Our professors do not define their expectations clearly.

(26) The materials used in language lessons motivate me.

(28) Our professors grade unfairly.

(33) I do not like our professors' teaching methods.

\section{Family Support}

(25) My family supports my decision to study Italian.

Attitudes towards Learning Italian and Italian in general

(2) I like studying Italian very much.

(5) I lose my will to study when I get a bad grade in an exam. *

(13) Studying Italian is a waste of time. *

(14) My professors' responses to my mistakes discourage me. *

(17) I prefer studying for Italian courses to studying for courses from other departments.

(19) I am gradually losing interest in studying Italian. *

(22) Studying Italian is a pleasure for me.

(30) I believe that Italian studies are boring. *

(31) I am eager to learn everything there is to know about the Italian language.

(1s) I sometimes regret enrolling in Italian studies.

(2s) Italian studies have completely met my expectations.

(3s) Italian studies require more effort than I expected.

(4s) I believe I am a successful Italian language student.

(5s) I am afraid I will never be able to use Italian with ease.

* reverse coded item 